\title{
The Adsorption of Silver-labelled Fungal Pigment by Bacterial and Apple Plant Ribosomes
}

\author{
By R. C. HIGNETT \\ East Malling Research Station, Maidstone, Kent \\ (Received I9 March I973; revised 8 May 1973)
}

SUMMARY

\begin{abstract}
Extracellular material produced by Venturia inaequalis (the apple scab disease organism) formed a tightly bound complex with silver. The silver complex (in aqueous solution) was taken up by whole detached apple leaves (cultivar MM I09) and was observed in the petiole cytoplasm as ribosome-like particles. Diffuse deposits of silver were observed in the cell walls.

The silver complex was also taken up by a proportion of the particles present in ribosome preparations made from apple-leaf tissues and from bacterial cultures. Such complexed ribosomes were apparently swollen by internal adsorption of the substance, some showing (in the electron microscope) a faint halo round the central core; the cleft between the sub-units was visible. Comparatively few ribosomes from Pseudomonas mors-prunorum showed strong affinity for the silver complex. The ribosomal particles were similar in most respects to the particles seen in treated leaf petioles. Silver-complexed particles prepared from isolated ribosomes were degraded by 'Pronase' to ragged skeletal remnants which were further digested by pancreatic ribonuclease. The latter enzyme did not attack intact particles.

The results support evidence from earlier work that the progress of the disease is partly controlled by the effects of fungal pigments on host solute transport (possibly mediated via the cell-wall membrane system) and on hormone-controlled plant metabolism and photosynthesis (via the protein-synthesizing system).
\end{abstract}

\section{INTRODUCTION}

Coloured substances made by the plant pathogen Venturia inaequalis have been shown to be closely implicated in the progress of the apple scab disease (Hignett \& Kirkham, 1967; Kirkham \& Hignett, 1973).

The extracellular metabolites produced in culture are unstable complex compounds (molecular weight range 5000 to 70000 by gel filtration) containing amino acids, longchain fatty acids, phosphorus and melanin; further details will be published elsewhere. The material used in these studies, generally referred to as pigment, is totally water-soluble and polydisperse in the ultracentrifuge. The individual components present have not yet been fully investigated. The work reported here was an attempt to discover the site of action of fungal pigment in the host plant. To this end, fungal pigment was isolated and labelled with silver, thereby rendering at least part of it electron-opaque and visible in treated tissue under the electron microscope. Some of the initial results have been published (Hignett, I969). 


\section{METHODS}

Venturia inaequalis was grown on $10 \%$ 'Oxoid' malt extract (Oxo Ltd., London) or on basal medium augmented with apple-twig extract (Kirkham \& Hignett, 1973). The published method was modified by the use of aqueous extracts $\left(100^{\circ} \mathrm{C}, 6 \mathrm{~h}\right)$ of shredded oneyear-old Edward VII twigs; and the methanol-butanol extraction was omitted.

Extracellular pigment was isolated (Hignett \& Kirkham, 1967) and the fraction precipitated by $75 \%$ ethanol was dialysed, mixed with $\mathrm{AgNO}_{3}$ (final concentration $0 . \mathrm{I} \mathrm{M}$ ) and immediately dialysed at room temperature to remove excess silver. The product was concentrated and filtered ( $0.45 \mu \mathrm{m}$ membrane filter, Millipore Ltd., London) before use.

Fast-growing leaves of apple cultivar MM Io9 were detached complete with petioles (length $20 \mathrm{~mm}$ approx.) and the cut ends placed in a solution of the pigment silver complex (P-Ag, $7 \mathrm{mg} / \mathrm{ml}$ ) for I $\mathrm{h}$. Petroleum jelly was applied to the petioles to prevent fluid creeping along the surfaces. Sections of petiole were then taken adjacent to the leaf blade, fixed in $5 \%(\mathrm{v} / \mathrm{v})$ formalin, dehydrated stepwise with alcohol and embedded in 'Epon' (Taab Laboratories, Reading, Berkshire). Control samples were taken from leaves that had been similarly treated with $0 \cdot 1 \mathrm{mM}-\mathrm{AgNO}_{3}$ or with silver-nitrate-treated bovine serum albumin or bovine pancreatic deoxyribonuclease.

Ribosomes were isolated from apple leaves (cultivar MM 109), which were ground to a slurry in ice-cold buffer (0.I M-tris- $\mathrm{HCl}, \mathrm{pH} 7.6$, containing $0.0 \mathrm{I} \mathrm{M}-\mathrm{KCl}, 0.015 \mathrm{M}-\mathrm{MgCl}_{2}$, Io \% 'Tween' 80 from. Koch-Light Ltd., Colnbrook, Buckinghamshire, and $0.005 \mathrm{M}-\beta$ mercaptoethanol), with acid-washed sand (w/w) in a cold mortar. The slurry was filtered under pressure on to Bentonite $(2 \mathrm{mg} / \mathrm{ml})$ and then centrifuged at $40000 \mathrm{~g}$ for $40 \mathrm{~min}$. Ribosomes were pelleted from the supernatant at $120000 \mathrm{~g}$ for $90 \mathrm{~min}$ and resuspended in buffer. The suspension was layered on to a sucrose gradient ( 5 to $20 \% \mathrm{w} / \mathrm{v}$ in buffer without 'Tween' or mercaptan) and spun at $35000 \mathrm{~g}$ (average) for $2 \mathrm{~h}$. The ribosomal fraction was then taken slowly from the bottom of the tube with a hypodermic needle. Bacterial ribosomes were prepared from cultures of Pseudomonas mors-prunorum after the bacteria had been disintegrated with glass ballotini for $15 \mathrm{~min}$ in a Mickle shaker (Mickle Engineering, Gomshall, Surrey) with the same buffer. Ribosomes were recovered from the cell sap $(\mathrm{I} 40000 \mathrm{~g}, 2 \mathrm{~h}$ ) after removal of bacterial debris in the centrifuge at $40000 \mathrm{~g}$ for $30 \mathrm{~min}$. A trace of deoxyribonuclease was added to all preparations at the first cell-free stage. Ribosomes were mixed with P-Ag $(5 \mathrm{mg} / \mathrm{ml})$ and left for 10 min at $20^{\circ} \mathrm{C}$. Samples were loaded on to electron-microscope grids, left for $5 \mathrm{~min}$ and then rinsed with water.

Enzymic digestions with 'Pronase' (Calbiochem, London) or pancreatic ribonuclease were done at $20^{\circ} \mathrm{C}$ in buffer without 'Tween' or mercaptan, adjusted to $\mathrm{pH} 6.8$ with $6 \mathrm{~N}-\mathrm{HCl}$. Digests were loaded immediately on to sample grids. After Io min the grids were drained, washed with 3 drops of distilled water, drained again, and air dried before examination in the slectron microscope.

\section{RESULTS}

In apple-leaf petiole sections examined directly in the electron microscope, no dense opaque"structures were seen in any of the control samples, but heavy leposits were observed in samples treated with P-Ag (Fig. I). Diffuse deposits were visible in the cell wall regions, and well defined particles ranging up to approximately $50 \mathrm{~nm}$ diameter were visible in the cytoplasm. Fig. 2 shows a double linear array of such particles (diameter approximately 20 to $55 \mathrm{~nm}$ ) lying on each side of a diffusely stained region. In both Figures many particles have the typical appearance of ribosomes, consisting of larger and smaller sub-units, often 


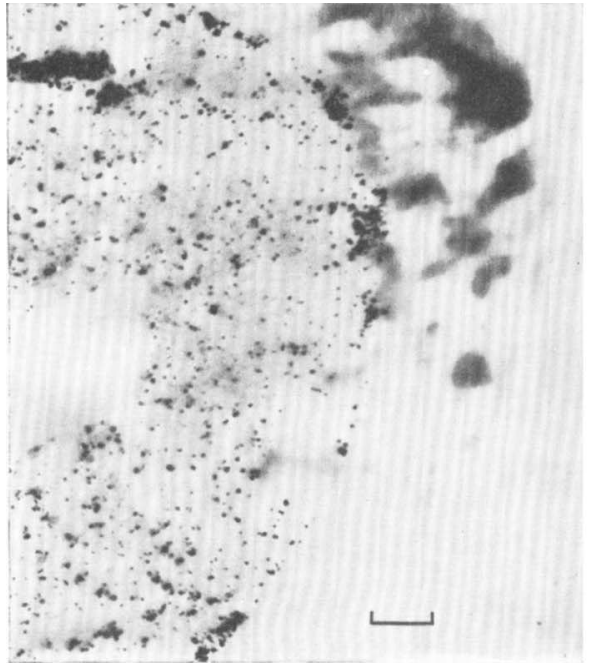

Fig. I

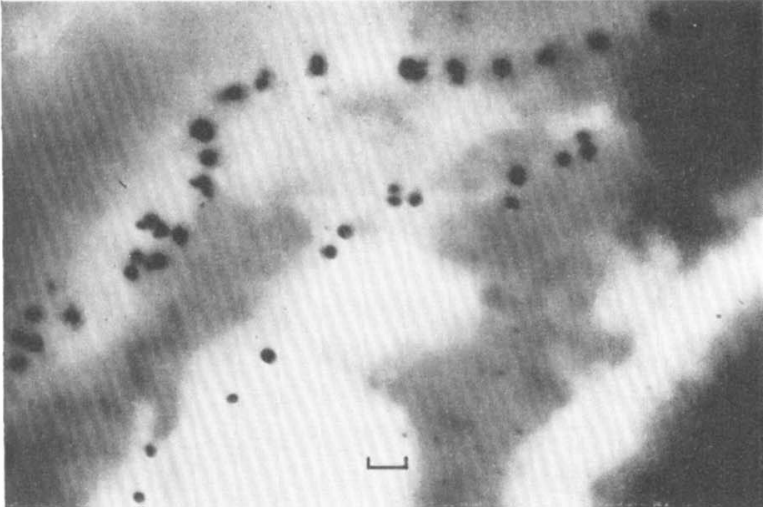

Fig. 2

Fig. I. Petiole section after uptake of P-Ag by detached leaf. The cell wall shows diffuse patches of silver (electron-opaque). Densely stained ribosome-like particles are visible in the cytoplasm. Bar marker represents $400 \mathrm{~nm}$.

Fig. 2. Linear array of ribosome-like particles in petiole section with diffusely stained material between the rows of particles, after uptake of P-Ag by detached leaf. Bar marker represents $100 \mathrm{~nm}$.

with a clearly visible cleft between the two. These particles are very similar in size and shape to those observed in cell-free preparations. In Fig. 2 a certain regularity can also be discerned in the linear spacing of the particles, which averages about $140 \mathrm{~nm}$ centre to centre. These particles fall into two size groups of approximately 40 to $47 \mathrm{~nm}$ and 20 to $33 \mathrm{~nm}$ diameter. A few of the particles show internal structure in the form of dense bands which range from 0.5 to $6 \mathrm{~nm}$ in width; diagrams are included for clarity (Fig. 3 and 4). The ratio of sub-unit diameters of many of the ribosome-like particles observed was $\mathrm{I} \cdot 6: \mathrm{I}$, a ratio very close to that measured in cell-free preparations.

Isolated apple-leaf ribosomes were examined before and after treatment with $\mathrm{P}-\mathrm{Ag}$, on carbon-film grids directly, and also after being shadowed with platinum. Fig. 5 shows unshadowed ribosome-like particles from preparations treated with P-Ag. Many of the particles show a dense core surrounded by a faint halo. The core generally has a distinctly irregular outline whereas the surrounding halo is smooth. Core diameters range about 25 and $40.5 \mathrm{~nm}$ for the smaller and larger sub-units respectively, the overall diameters being approximately 50 to $66 \mathrm{~nm}$. Shadowed samples of P-Ag-treated preparations showed many more particles than were visible in unshadowed samples. The shadowed preparations showed that ribosome suspensions treated with P-Ag contained many apparently normalsize ribosomes that occurred singly and in groups linked by thread, as in normal untreated samples. Diameters ranged from approximately $18 \mathrm{~nm}$ (small sub-unit) to $28 \mathrm{~nm}$ (large sub-unit), some variation in size being due to the effects of the shadowing technique.

Comparatively few P-Ag particles were seen in treated bacterial-ribosome suspensions, but those observed showed all the characteristics of particles prepared from apple-leaf ribosomes with the possible exception of the outer halo, which was not readily detected. The ratio of the diameters of sub-units in untreated cell-free ribosomes from plants and bacteria was approximately $1 \cdot 5: 1$ (mean of 10 measurements), as was that of the larger 

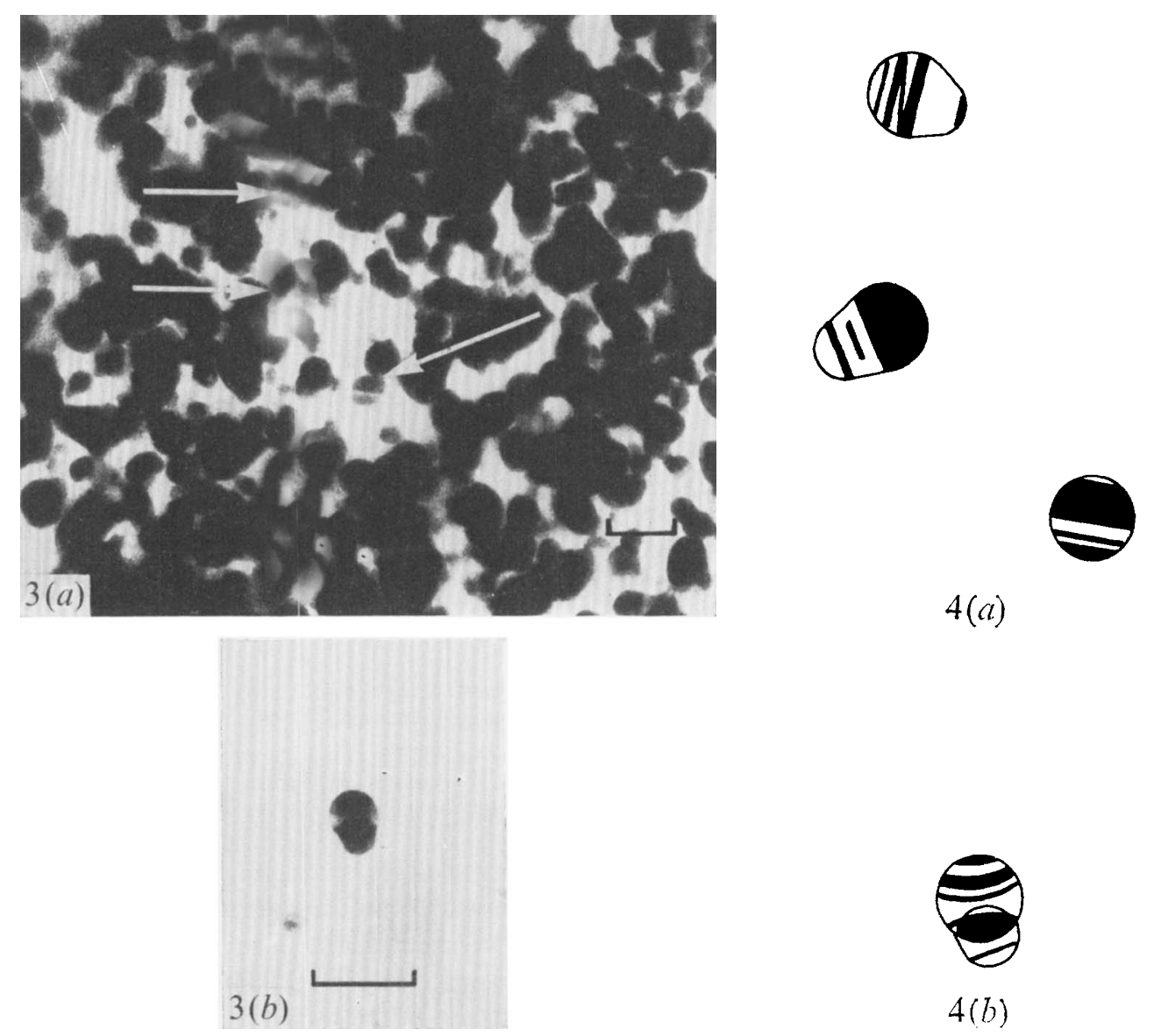

$4(b)$

Fig. $3 a$ and $b$. Bands (arrowed) observed on some particles in P-Ag-treated petioles. Bar marker represents $50 \mathrm{~nm}$.

Fig. $4 a$ and $b$. Diagrammatic representation of Fig. $3 a$ and $b$ (not to scale).

silver-complexed particles. No similar large particles were observed in shadowed, untreated ribosome preparations.

Although P-Ag tended to form aggregates when concentrated, no ribosome-like particles were detected, and the aggregates were not digested by either 'Pronase' or pancreatic ribonuclease. The silver-complex particles seen in all treated cell-free ribosome suspensions were degraded by 'Pronase', giving ragged skeletal particles of up to $50 \mathrm{~nm}$ diameter (Fig. 6). These particles were destroyed by additional digestion with pancreatic ribonuclease. Ribonuclease did not visibly damage intact ribosomal P-Ag particles. Ribosome-like aggregates were not formed in mixtures of P-Ag with either 'Pronase' or ribonuclease, in the absence of ribosomes.

\section{DISCUSSION}

The results show that at least part of the polydisperse fungal pigment produced by the agent of apple scab disease formed a silver complex which was taken up by apple-plant tissue in vivo, when diffuse heavy deposits were observed in the cell wall and also in ribosomelike particles in the cytoplasm. The particles were not observed in the cell wall nor in the 


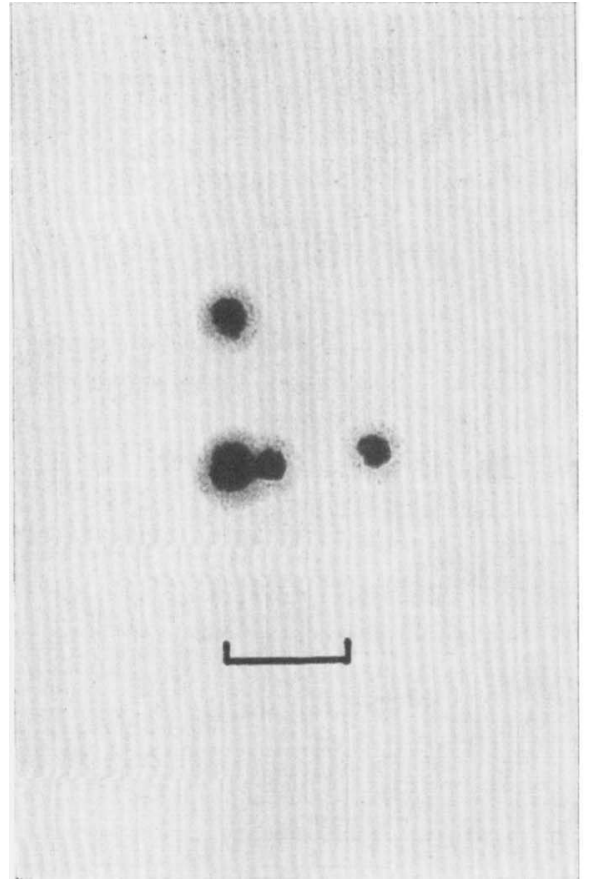

Fig. 5

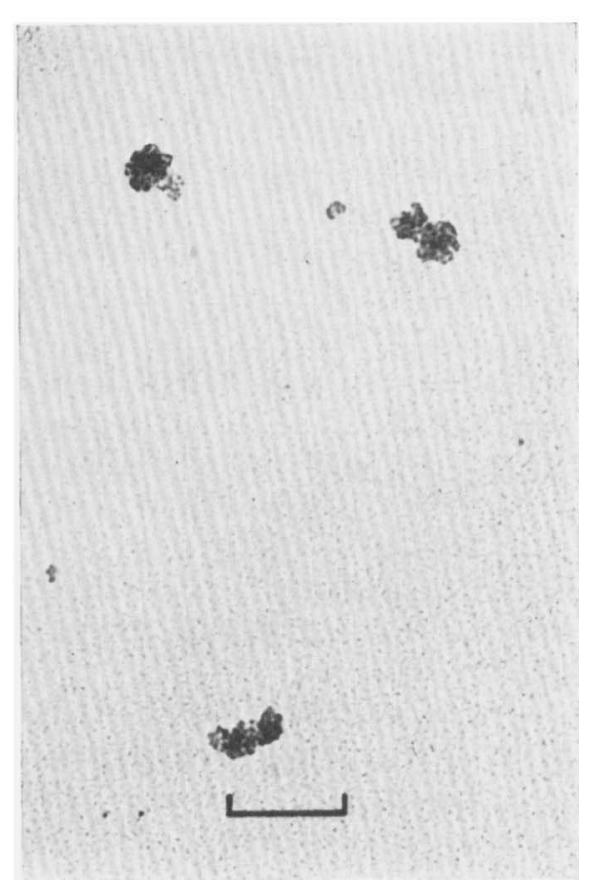

Fig. 6

Fig. 5. Apple-leaf ribosomes after isolation and treatment with P-Ag (not shadowed). The dense central cores are surrounded by lighter haloes. Bar marker represents $100 \mathrm{~nm}$.

Fig. 6. Ribosome/P-Ag complex after digestion with 'Pronase'. Bar marker represents $100 \mathrm{~nm}$.

intercellular spaces. Apart from the generally distributed particles in the cytoplasm, nonrandom arrays occurred in association with diffusely stained material, suggestive of membrane-bound ribosomes. The dense particles observed in leaf petiole sections showed greater heterogeneity in size, varying up to $55 \mathrm{~nm}$ diameter, than is observed in normal plant ribosomes. However, these particles lay exactly in the size range of plant and bacterial particles formed by treatment of isolated ribosomes with $\mathrm{P}-\mathrm{Ag}$, and were also very similar in respect of shape and ratio of sub-unit diameters, and in their occurrence only in the presence of ribosomes. The striped effect seen in some particles in situ was not readily discerned in cell-free preparations.

Treated ribosomal preparations of plant and bacterial origin gave rise to ribosome-like particles which were degradable by 'Pronase' and ribonuclease, but not by ribonuclease alone. The particles observed ranged up to $66 \mathrm{~nm}$ diameter, approximately three times the size of normal ribosomes. Abnormally large particles were not observed in ribosome preparations before treatment with $\mathrm{P}-\mathrm{Ag}$.

The size of shadowed apple-plant ribosomes not complexed with P-Ag contrasts with the size of the cell-free particles containing P-Ag seen alone in unshadowed preparations. The dense cores of the latter were approximately $7 \mathrm{~nm}$ and $\mathrm{I} 2 \mathrm{~nm}$ bigger than the smaller and larger sub-units, respectively, of the former. Many of the particles rendered visible by shadowing were within the size range expected of normal plant ribosomes, approximately I 5 to $30 \mathrm{~nm}$ (Bruskov \& Odintsova, 1968; Miller, Karlsson \& Boardman, I966), indicating that the larger particles containing silver seen in isolated ribosomal preparations were 
swollen or enlarged by the adsorption process. The halo seen around unshadowed cell-free $\mathrm{P}$-Ag particles suggests that the silver-complex was adsorbed internally causing them to swell, or possibly that the complex 'snowballed' loosely on to the central core. Clefts visible in P-Ag-treated particles were similar to those observed in some ribosomes isolated from pea and bean tissues (Bruskov \& Odintsova, 1968). The skeletal appearance of cell-free particles after digestion with 'Pronase' was reminiscent of the surface features on bacterial ribosomes revealed by the work of Hart (1965), and may provide a means of investigating ribosome morphology.

The bacterial ribosomes formed large P-Ag particles similar in all respects to those given by plant ribosomes, with the possible exception of the outer halo, which was not easily detected. This effect and the markedly smaller number of P-Ag particles formed may be linked with the type of ribosome present in the preparations used. The plant material used contained a mixed population of cytoplasmic and chloroplast ribosomes.

Aggregates were formed by P-Ag alone under certain conditions of concentration. Such non-ribosomal aggregates were characterized by their angularity, their faceted or crystalline appearance, their smooth hard outline and their random juxtaposition. Although some aggregates were observed in which stripes were visible, these features were generally very sharply defined and often occurred in sets at $45^{\circ}$ to each other, in crystalline fashion. Nonribosomal aggregates such as these were not readily seen in sections taken from petioles treated in vivo. On the contrary, the particles seen in Fig. 2 in particular present a uniform non-crystalline aspect in respect of size, shape and position which argues against them being random aggregates. Aggregates of P-Ag were not visibly attacked by 'Pronase', unlike the ribosome-like particles seen in treated ribosome preparations. The evidence presented thus strongly supports the suggestion that P-Ag can be adsorbed by ribosomes both in vitro and in vivo. Since the effect of silver on the immunological properties of proteins appears to be insignificant (Kolchakov \& Kantardjiev, 1965) the P-Ag-ribosome adsorption reaction is unlikely to be an artefact.

The failure of various other proteinaceous materials to transport silver to the ribosome sites in vivo and the failure of free silver ion to accumulate there, strongly suggest that the silver complex was adsorbed in undissociated form. The apparently selective adsorption of $\mathrm{P}-\mathrm{Ag}$ by some particles in the cell-free ribosomal preparations also supports the view that the complex was not dissociated during the experiments, and may reflect the different types of ribosome used or the variation of ribosomal constituents noted by Craven, Voynow, Hardy \& Kurland (I969). The fact that some bacterial ribosomes adsorbed P-Ag suggests that aspects of host-parasite specificity involving fungal pigment are not expressed at the ribosomal level.

The results given here support the view that the parasite elaborates substances which may interfere with the functioning of the host cell wall (and hence with solute transport) and also with host metabolism at the site of protein synthesis. Previous work with fungal pigment and kinetin has indicated that solute transport and the hormone system of infected plants are closely associated with the scab disease, which is also affected by incident light (Hignett \& Kirkham, 1967; Kirkham \& Hignett, 1973). Plant hormones have been involved with the ribosome/polyribosome system (Evins \& Varner, I972; Trewavas, I968), with RNA and protein synthesis (Srivastava \& Arglebe, 1968; VonAbrams \& Pratt, 1968), and with the light incident upon the plants (Back \& Richmond, I969; Jackson \& Field, 1972). The results reported to date could be explicable in terms of effects exerted near a common locus, which it is suggested is at, or is associated with, the hormone-ribosome system. 
Acknowledgements are due to Dr A. B. Beakbane and Miss M. M. Fuller for the electron micrographs, and to A. Quirk and A. L. Roberts for technical assistance.

\section{REFERENCES}

BACK, A. \& Richmond, A. (I969). An interaction between the effects of kinetin and gibberellin in retarding leaf senescence. Physiologia plantarum 22, I207-1 216.

Bruskov, V. I. \& Odintsova, M. S.(I968). Comparative electron microscopic studies of chloroplast and cytoplasmic ribosomes. Journal of Molecular Biology 32, 47I-473.

Craven, G. R., Voynow, P., Hardy, S. J. S. \& Kurland, C. G. (1969). The ribosomal proteins of Escherichia coli. II. Chemical and physical characterisation of the $30 \mathrm{~S}$ ribosomal proteins. Biochemistry 8 , 2906-2915.

EVINS, W. H. \& VARNeR, J. E. (I972). Hormonal control of polyribosome formation in barley aleurone layers. Plant Physiology 49, 348-352.

Hart, G. R. (1965). Surface features of the $50 \mathrm{~S}$ ribosomal component of Escherichia coli. Proceedings of the National Academy of Sciences of the United States of America 53, 1415-1420.

Hignetr, R. C. (1969). Apple plant ribosomes and Venturia inaequalis (apple scab). Abstracts of the 6th Meeting, Federation of European Biochemical Societies, Madrid I I 3.

HignetT, R. C. \& KIRKHAM, D. S. (1967). The role of extracellular melanoproteins of Venturia inaequalis in host susceptibility. Journal of General Microbiology 48, 269-275.

JACKSON, D. I. \& FIELD, R. J. (I972). Light and hormone interaction in apical dominance in Phaseolus vulgaris L. Annals of Botany 36, 525-532.

Kirkham, D. S. \& Hignett, R. C. (I973) Factors affecting the severity of the apple scab disease and its vertical distribution on shoots of the apple rootstock MM 109. In 3rdLong Ashton Symposium (1971): Fungal Pathogenicity and The Plant s Response, pp. 55-66. Edited by R. J. W. Byrde and C. V. Cutting. London: Academic Press.

Kolchakov, K. \& Kantardiev, V. (1965). Immunological characteristics of silver-labelled proteins. Compte rendu de l'Académie bulgare $\mathbf{1 8}, 353-365$.

Miller, A., Karlsson, U. \& Boardman, N. K. (1966). Electron microscopy of ribosomes isolated from tobacco leaf. Journal of Molecular Biology r7, 487-489.

Srivastava, B. I. S. \& Arglebe, C. (I968). Effect of kinetin on ribosomes of excised barley leaves. Physiologia plantartum 21, 85I-857.

Trewavas, A. (1968). The effect of 3-indolylacetic acid on the levels of polysomes in etiolated pea tissue. Phytochemistry 7, 673-681.

Von Abrams, G. J. \& Pratt, H. K. (I968). Effect of the kinetin-naphthaleneacetic acid interaction upon total RNA and protein in senescing detached leaves. Plant Physiology 43, I27I-I 278. 